\title{
SARS-CoV-2 and the nose
}

\author{
Risks and implications for primary care
}

\section{Raewyn G Campbell}

\section{Background}

General practitioners (GPs) have some of the highest rates of mortality from COVID-19 among healthcare workers. SARS-CoV-2 has unique properties that place GPs at particular risk.

\section{Objective}

The aim of this article is to discuss the nose-related features of SARS-CoV-2 that place GPs at risk, and to make recommendations pertinent to the safety and protection of primary healthcare physicians.

\section{Discussion}

The highest viral load of SARS-CoV-2 is in the nose and nasopharynx. It is often highest early in the illness, before the development of symptoms. Further, SARS-CoV-2 replicates and continues to shed in the nasopharynx long after the virus is no longer detectable in the lower respiratory tract. This places any physician performing examinations on, or procedures involving, the upper respiratory tract at risk for contracting COVID-19. New-onset hyposmia and dysgeusia are indicators for COVID-19 and should be included in screening protocols.
FRONTLINE HEALTHCARE WORKERS have a threefold greater risk of becoming infected with SARS-CoV-2 than the general community. ${ }^{1}$ In fact, many healthcare workers have died from COVID-19, the disease caused by SARS-CoV-2. ${ }^{2}$ Initially, the highest incidence of nosocomial infection was in otolaryngologists in China. ${ }^{3}$ However, more recent data suggest the majority of physician deaths have been general practitioners (GPs) and emergency physicians (42.5\%), with only $4 \%$ of deaths occurring in ear, nose and throat (ENT) surgeons. ${ }^{2}$ This is most likely due to the sheer volume of patients with COVID-19 seen by these specialties, as well as limited personal protective equipment (PPE).

This article focuses on the unique features of SARS-CoV-2 that place any healthcare provider performing a procedure involving the upper respiratory tract (URT) at risk. Recommendations will also be made, focusing on protecting the primary healthcare physician working in the COVID-19 era.

\section{Coronaviruses}

Human coronaviruses are thought to have originated $500-800$ years ago. ${ }^{3}$ Coronaviruses are enveloped RNA viruses surrounded by spike-shaped glycoproteins (Figure 1). They have the largest genome of all RNA viruses, three times larger than human immunodeficiency virus and hepatitis $C$ virus, and twice the size of influenza virus. ${ }^{4}$
Coronaviruses are equipped with a genomic proofreading mechanism that prevents the accumulation of harmful mutations. ${ }^{4}$ Antiviral drugs, which weaken viruses by inducing mutations in viruses, are notoriously unsuccessful in eradicating coronaviruses because of this proofreading mechanism. ${ }^{4}$ Human coronaviruses are thought to originate in animals, such as the horseshoe bat, and to infect humans via an animal intermediary or amplification host (Figure 2). ${ }^{5}$ It is not known in which animals SARS-CoV-2 originated; however, bats are thought to be the most likely reservoir. ${ }^{6}$

\section{SARS-CoV-2 and the nose}

SARS-CoV-2 enters the cell via the angiotensin converting enzyme-2 (ACE2) receptor. ${ }^{7}$ The viral spike proteins bind to the ACE2 receptors and then are activated by a second enzyme, transmembrane protease serine 2 (TMPRSS2), which permits fusion of the viral membrane with the cell membrane and entry into the cell. ${ }^{7}$ SARS-CoV-2 binds to the ACE2 receptor with 10-20-fold greater affinity than SARS-CoV. ${ }^{8}$ ACE2 and TMPRSS2 have been found to be expressed together in nasal goblet secretory cells and nasal ciliated epithelium, pulmonary type II pneumocytes in alveoli and ileal absorptive enterocytes. ${ }^{9}$ Unlike SARS-CoV, SARS-CoV-2 can infect and reproduce in the URT. ${ }^{4}$ ACE2 expression is highest in the nasal ciliated epithelium, and ACE2 expression shows a gradient of lessening expression when moving from the upper 
airways to the lower airways (bronchioli and alveoli). ${ }^{10}$ It has since been discovered that the nasopharynx has a higher viral load and a higher viral replication rate than the oral cavity and lower respiratory tract (LRT) ${ }^{10-12}$ Further, SARS-CoV-2 has been detected in the middle ear and mastoid, suggesting transmission via the nasopharynx and eustachian tube. ${ }^{13}$ The viral load is also highest in the early phase of the illness, peaking 2-3 days prior to, or on the day of, symptom onset and then reducing thereafter. ${ }^{14}$ The viral load in asymptomatic patients is similar to that in symptomatic patients. ${ }^{11}$ These findings support concerns regarding asymptomatic transmission.

Shedding of the virus in the nose is very high early in the course of the virus and precedes LRT shedding. ${ }^{12}$ Further,

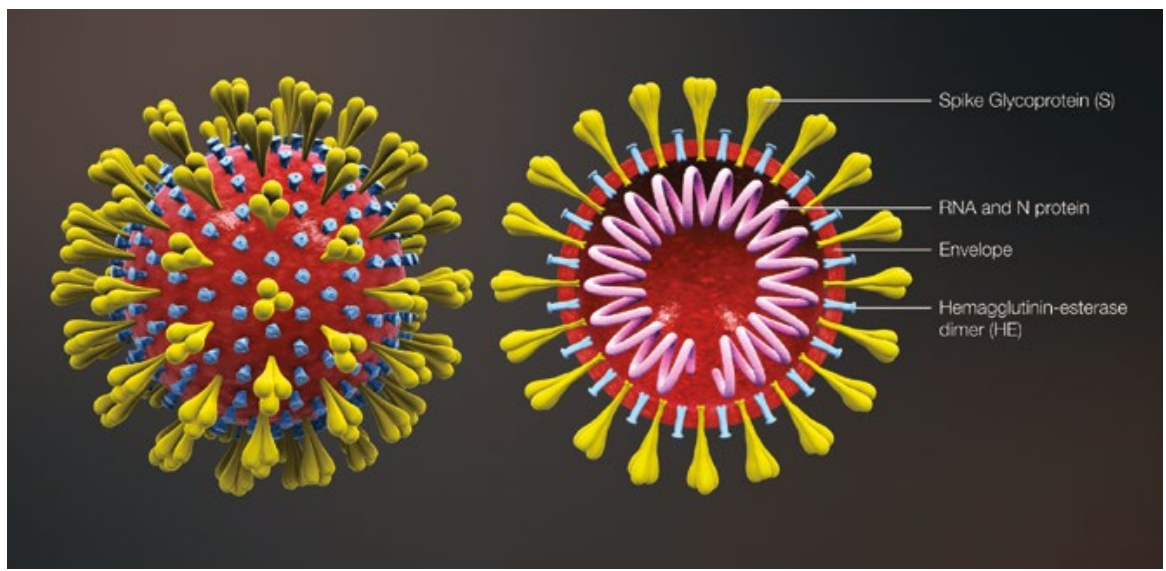

Figure 1. Coronavirus virion structure showing the spike glycoproteins

Reproduced from Wikimedia Commons. File: 3D medical animation corona virus.jpg, licensed under CC BY-SA 4.O. Available at https://commons.wikimedia.org/wiki/File:3D_medical_animation_corona_virus.jpg [Accessed 22 August 2020].

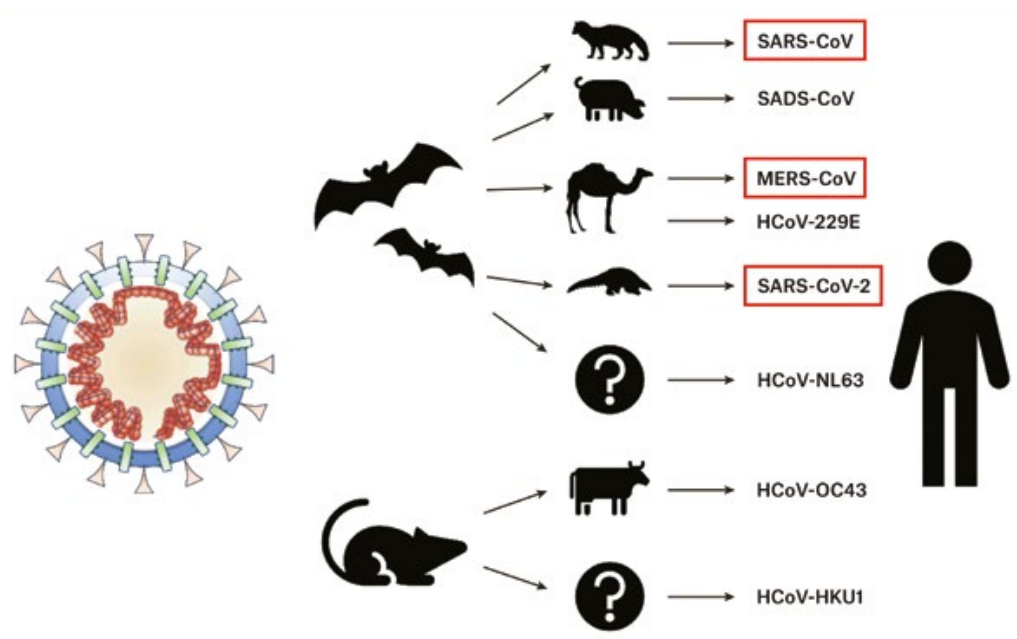

Figure 2. Zoonosis and coronaviruses. The pangolin is suspected as the intermediary in SARS-CoV-2 zoonosis from bats to humans.

Reproduced with permission from Rabi FA, Al Zoubi MS, Kasasbeh GA, Salameh DM, Al-Nasser AD, SARS-CoV-2 and coronavirus disease 2019: What we know so far, Pathogens 2020;9(3):231, doi: 10.3390/ pathogens 9030231.

shedding in the URT may continue after the virus is no longer detectable in the LRT and also after recovery. ${ }^{12}$ It is therefore thought that the major mode of transmission of SARS-CoV-2 is via the URT. ${ }^{15}$ In fact, the nasal epithelium may be the initial site for SARS-CoV-2 respiratory tract infection. ${ }^{10}$ As $90 \%$ of inspiration is via the nose, this may partially explain the high transmission rate of SARS-CoV-2. ${ }^{16}$

\section{COVID-19 and the nose}

Surprisingly, there is a paucity of sinonasal symptoms associated with COVID-19. Rhinorrhoea and nasal obstruction have been described; however, more recently, sudden onset of olfactory and gustatory dysfunction has been described in up to $85.6 \%$ and $98 \%$ of patients with COVID-19, respectively. ${ }^{17-21}$ Many of these patients had no other sinonasal signs or symptoms; few, if any, had other symptoms of COVID-19. ${ }^{20,22}$ In fact, olfactory dysfunction was the presenting symptom in up to $26.6 \%$ of patients. ${ }^{18,20,23}$ In a French study, $94 \%$ of patients presenting with anosmia tested positive for SARS-CoV-2. ${ }^{24}$ Olfactory dysfunction is more common in women with COVID-19 than in men and in younger patients (median age 56 years in olfactory dysfunction group, compared with 66 years in group without olfactory dysfunction), ${ }^{25}$ and it may be associated with a milder clinical course. ${ }^{18,25,26}$ Sudden loss of smell or taste may therefore be a marker of COVID-19 and should be part of any screening protocol. Olfaction usually starts to recover after 5-10 days, with the most significant improvement occurring in the first two weeks. ${ }^{20}$ Most patients recover fully. ${ }^{20,24}$

Coronaviruses are known to have neurotropic properties affecting the olfactory neurons and entering the central nervous system via the olfactory bulb. ${ }^{27}$ SARS-CoV-2 has been found to target the central nervous system and therefore has neuroinvasive potential. ${ }^{28-30}$ However, ACE2 has not been detected in olfactory sensory neurons or olfactory bulb neurons but, in fact, in the sustentacular cells of the olfactory epithelium and olfactory bulb vascular pericytes. ${ }^{31}$ The fact that 
SARS-CoV-2 infects non-neuronal cell types may explain why most patients with olfactory impairment recover.

\section{Droplet versus aerosol}

The definition of an aerosol is controversial. Essentially, an aerosol is any liquid or solid particle suspended in air and generated when air passes over a layer of fluid. ${ }^{32,33}$ Large droplets will fall to the ground before they evaporate and transmit disease via droplet or contact spread. ${ }^{34}$ Smaller aerosols remain airborne for longer periods (potentially evaporating before they land on a surface) and transmit disease via airborne transmission. ${ }^{35,36}$ A sneeze can generate approximately 46,000 large droplets and up to 1,100,000 small droplet nuclei (the residual dried droplet), travelling at anywhere from $4.5 \mathrm{~m} / \mathrm{s}$ to $100 \mathrm{~m} / \mathrm{s.}^{37-40}$ Each droplet contains up to 200 million virus particles. ${ }^{41}$ In practical terms, aerosols $<10 \mu \mathrm{m}$ in diameter are able to penetrate into the lower airways and alveoli, while particles $10-100 \mu \mathrm{m}$ are more likely to be deposited in the URT. ${ }^{42}$ It is unclear whether SARS-CoV-2 is transmitted via aerosol, droplet or direct inoculation via fomites. However, all three routes are possible. Aerosolised viable SARS-CoV-2 has been noted to remain airborne for up to three hours, and viable virus can survive on certain surfaces, such as plastic and stainless steel, for up to 72 hours. ${ }^{43}$ Aerosolised SARS-CoV-2 RNA has been detected in the air up to $4 \mathrm{~m}$ from a patient. ${ }^{44}$ Whether this RNA represented viable virus is not known. However, SARS-CoV-2 has been shown to maintain infectivity and integrity in aerosol form for up to 16 hours. ${ }^{45} \mathrm{~A}$ recent article also found that both sneezing and spraying the nose generated a significant and equivalent amount of airborne aerosols. ${ }^{46}$ These were greater than with speech, which was also noted to generate aerosols above background levels. ${ }^{46}$ Interestingly, panting and coughing did not generate aerosols above background levels. ${ }^{46}$ This same article also noted that, while attenuating airborne aerosols, surgical masks still permitted a significant amount of aerosol escape. ${ }^{46}$ An N95 respirator mask successfully attenuated aerosols to background levels. ${ }^{46}$

\section{The risk and implications for primary care}

The initial high infection rate among ENT surgeons in China was due to lack of awareness of SARS-CoV-2, lack of appropriate PPE, direct contact with patients' URT mucosa, and aerosol- or droplet-generating diagnostic and therapeutic procedures frequently performed during ENT examinations. ${ }^{47}$ Rhinological surgical procedures often generate aerosols and droplets from the sinonasal cavities and nasopharynx, and they are therefore considered high risk. ${ }^{48,49}$ However, with increased awareness and use of PPE, this infection rate has dropped dramatically. It must be noted that the risk for each practitioner will vary depending on the prevalence of COVID-19 in their patient population. Studies have shown that no nosocomial transmission occurred when appropriate PPE was worn. ${ }^{50,51}$ More specifically, face masks, physical distancing (greater than $1 \mathrm{~m}$ ) and eye protection have been shown to significantly reduce COVID-19 infection rates. ${ }^{52,53}$ Therefore, patients should be required to wear a mask to appointments.

The rate of respiratory viral isolation in the sinonasal cavity has been found to be higher in inflammatory sinonasal conditions when compared with normal controls. ${ }^{54}$ Therefore, to keep the sinonasal mucosa as healthy as possible, intranasal steroid treatment for inflammatory sinonasal diseases should not be ceased during the COVID-19 era.

Children with COVID-19 are often asymptomatic. Studies from China found that $94 \%$ of children had no, mild or moderate symptoms, and $55 \%$ had no or very mild symptoms only. ${ }^{55}$ In comparison to adults, children experience fewer symptoms of cough, fever, headache and shortness of breath, although a rare and novel vasculitic disease has been described in some children with COVID-19. ${ }^{56}$

It is important that healthcare workers exercise caution when performing aerosolor droplet-generating procedures, when examining the URT and when examining children. An aerosol-generating procedure is one that generates aerosols in addition to those normally generated by the patient from breathing or talking. ${ }^{35}$ This includes procedures that provoke a sneeze or cough. Commonly performed aerosol- or dropletgenerating procedures in the primary care setting include: applying nasal prong oxygen, spraying the nose, taking nasal and/or oral swabs, using nebulisers and performing nasendoscopy and spirometry. Appropriate PPE is crucial during these procedures, and the number of staff exposed should be kept to a minimum. Appropriate PPE for aerosol-generating procedures includes a surgical or N95 mask, goggles or a visor, a waterproof gown with full length sleeves (ideally with thumb hooks) if significant aerosolisation is expected, gloves that cover the sleeves of the gown and a cover for the hair.

Appropriate ventilation may remove up to $60 \%$ of airborne droplets with each air exchange. ${ }^{33}$ A surgical mask and goggles/ eye protection, as a minimum, should be worn when taking a history from a patient because of the aerosols generated from speech. ${ }^{46}$ It is important that full PPE is worn for examination of the nasal or oral cavities as, while not technically aerosol generating, examination carries an increased potential for provoking a sneeze or a cough while the practitioner is in close proximity. Further, many patients will automatically vocalise during an oral exam. Although asking the patient to say 'aah' elevates the soft palate, thereby improving the view of the oropharynx and permitting evaluation of symmetry of palatal elevation, patients should be discouraged from vocalising during an oral cavity exam unless it is pertinent to their presenting symptoms. A tongue depressor should be used only when necessary and advanced slowly to avoid stimulating the gag reflex in sensitive patients. Ear syringing may stimulate the auricular branch of the vagus nerve and cause patients to cough. Therefore, patients should be wearing a mask if this procedure is required. It is also recommended to avoid asking a patient with a known tympanic membrane perforation to perform a Valsalva manoeuvre, as SARS-CoV-2 has been 
detected in the middle ear and mastoid cavity. ${ }^{13}$ If performing nasal cautery, it is important that the nasal mucosa is well anaesthetised prior to avoid stimulating a sneeze. Rather than using a nasal anaesthetic spray, cotton wool can be soaked in the anaesthetic and placed on the nasal mucosa for 5-10 minutes prior to cautery. The patient should be wearing a face mask that can be lowered to still cover the mouth during this procedure. If the patient feels a sneeze coming on, pinching the end of the nose will usually stem this reflex (Figure 3).

As a result of the rapidly changing environment, GPs can access the Australian Government website for current Australian PPE recommendations (www.health.gov.au/news/ health-alerts/novel-coronavirus2019-ncov-health-alert/ coronavirus-covid-19-advice-forthe-health-and-aged-care-sector/ personal-protective-equipment-ppe-forthe-health-workforce-during-covid-19). ${ }^{57}$

It is recommended that surfaces be cleaned with either 2-3\% hydrogen peroxide, a hospital-grade antiviral disinfectant, 2-5 g/L chlorine solution or solutions containing a minimum of $75 \%$ alcohol. ${ }^{58,59}$ Soap and water is the most effective method for hand washing.

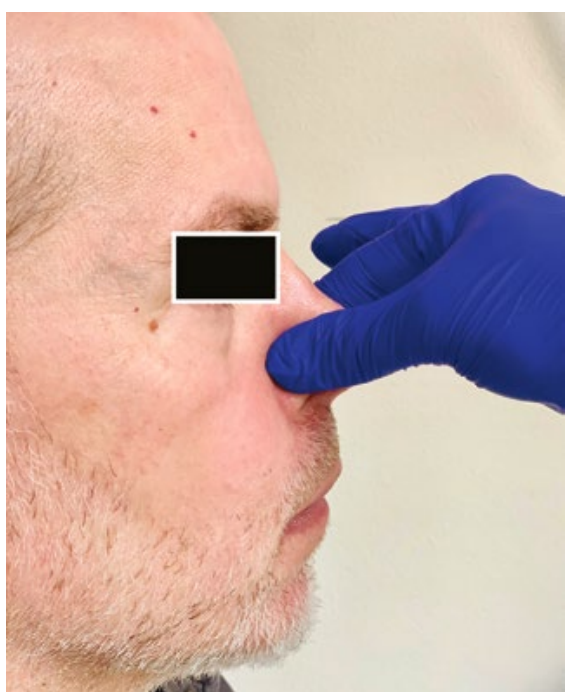

Figure 3. Pinching the tip of the nose to stem the sneeze reflex
However, if using hand sanitiser, it is recommended that a formula with a minimum of $60 \%$ alcohol be used. ${ }^{60}$ The formula recommended by the World Health Organization contains $80 \%$ ethanol or $75 \%$ isopropyl alcohol. ${ }^{60}$ These recommendations should not replace those made by the practitioners' local health authority. Many healthcare workers change clothes before entering the home and place them in a plastic bag. Shoes are left outside. They shower in hot water using soap as soon as they arrive home, and they wash their clothes with detergent in hot water.

\section{Conclusion}

The sinonasal cavity is an important route of entry and infection for SARS-CoV-2 and carries the highest viral load in the respiratory tract. Sinonasal secretions are an important source of transmission and may place healthcare workers at risk, particularly as sinonasal symptoms (apart from anosmia) do not appear to be a predominant clinical component of COVID-19. Sudden onset of anosmia or hyposmia is likely to be a specific indicator for COVID-19 and should be included in any screening protocol. Finally, it is important that particular care is taken when examining the URT, particularly in children, during the COVID-19 era. Guidance for PPE should be sought from the local health authority. The recommendations in this article should not replace those of the practitioners' governing health authority.

\section{Author}

Raewyn G Campbell FRACS, BMed (Hons), GradDipEx\&SportSc, BAppSc(Physio), FARS, Visiting Medical Officer, Department of Otolaryngology, Head and Neck Surgery, Royal Prince Alfred Hospital, NSW; Visiting Medical Officer, Department of Otolaryngology, Head and Neck Surgery, Macquarie University Hospital, NSW; Visiting Medical Officer, Department of Otolaryngology, Head and Neck Surgery, Sydney Adventist Hospital, NSW; Visiting Medical Officer, The ENT Centre, NSW; Clinical Associate Professor, Macquarie University, NSW. raewyn.campbell@gmail.com

Competing interests: None.

Funding: None.

Provenance and peer review: Not commissioned, externally peer reviewed.

\section{Acknowledgements}

The author would like to thank Dr Charissa Ho.

\section{References}

1. Nguyen LH, Drew DA, Graham MS, et al. Risk of COVID-19 among front-line health-care workers and the general community: A prospective cohort study. Lancet Public Health 2020. doi: 10.1016/ S2468-2667(20)30164-X. [ePub ahead of print]

2. Ing EB, Xu AQ, Salimi A, Torun N. Physician deaths from corona virus disease (COVID-19). medRxiv 2020. 04.05.20054494. doi: 10.1101/2020.04.05.20054494.

3. Che C. Europe's doctors repeat errors made in Wuhan, China medics say. Bloomberg News. 17 March 2020. Available at www.bloomberg.com/ news/articles/2020-03-17/europe-s-doctorsgetting-sick-like-in-wuhan-chinese-doctors-say [Accessed 22 August 2020].

4. Cyranoski D. Profile of a killer virus: The complex biology powering the coronavirus pandemic. Nature 2020;581(7806):22-26. doi: 10.1038/ d41586-020-01315-7.

5. Sheahan T, Rockx B, Donaldson E, Corti D, Baric R. Pathways of cross-species transmission of synthetically reconstructed zoonotic severe acute respiratory syndrome coronavirus. J Virol 2008;82(17):8721-32. doi: 10.1128/JVI.00818-08.

6. Rabi FA, AI Zoubi MS, Kasasbeh GA, Salameh DM, Al-Nasser AD. SARS-CoV-2 and coronavirus disease 2019: What we know so far. Pathogens 2020;9(3):231. doi: 10.3390/pathogens9030231.

7. Hoffmann $\mathrm{M}$, Kleine-Weber $\mathrm{H}$, Krüger $\mathrm{N}$, Müller M, Drosten C, Pöhlmann S. The novel coronavirus 2019 (2019-nCoV) uses the SARS-coronavirus receptor ACE2 and the cellular protease TMPRSS2 for entry into target cells. bioRxiv 2020:2020.01.31.929042. doi: 10.1101/2020.01.31.929042.

8. Wrapp D, Wang N, Corbett KS, et al. Cryo-EM structure of the 2019-nCoV spike in the prefusion conformation. Science 2020;367(6483):1260-63. doi: 10.1126/science.abb2507.

9. Sungnak W, Huang N, Bécavin C, Berg M. SARSCoV-2 entry genes are most highly expressed in nasal goblet and ciliated cells within human airways. Nat Med 2020;26:681-87. doi: 10.1038/ s41591-020-0868-6.

10. Hou YJ, Okuda K, Edwards CE, et al. SARS$\mathrm{CoV}-2$ reverse genetics reveals a variable infection gradient in the respiratory tract. Cell 2020;182(2):429-46.e14. doi: 10.1016/j. cell.2020.05.042

11. Zou L, Ruan F, Huang M, et al. SARS-CoV-2 viral load in upper respiratory specimens of infected patients. N Engl J Med 2020;382(12):1177-79. doi: 10.1056/NEJMc2001737.

12. Kim JY, Ko JH, Kim Y, et al. Viral load kinetics of SARS-CoV-2 infection in first two patients in Korea. J Korean Med Sci 2020;35(7):e86. doi: 10.3346/jkms.2020.35.e86.

13. Frazier KM, Hooper JE, Mostafa HH, Stewart M. SARS-CoV-2 virus isolated from the mastoid and middle ear: Implications for COVID-19 precautions during ear surgery. JAMA Otolaryngol Head Neck Surg 2020:e201922. doi: 10.1001/ jamaoto.2020.1922. [ePub ahead of print]

14. He X, Lau EHY, Wu P, et al. Temporal dynamics in viral shedding and transmissibility of COVID-19. Nat Med 2020;26:672-75. doi: 10.1038/s41591020-0869-5.

15. Rothe $C$, Schunk M, Sothmann P, et al. Transmission of 2019-nCoV infection from an asymptomatic contact in Germany. N Engl J Med 2020;382(1):970-71. doi: 10.1056/NEJMc2001468.

16. Camner P, Bakke B. Nose or mouth breathing? Environ Res 1980;21(2):394-98. doi: 10.1016/00139351(80)90042-0. 
17. Eliezer M, Hautefort $C$, Hamel AL, et al. Sudden and complete olfactory loss function as a possible symptom of COVID-19. JAMA Otolaryngol Head Neck Surg 2020. doi: 10.1001/jamaoto.2020.0832. [ePub ahead of print]

18. Lechien JR, Chiesa-Estomba CM, De Siati DR, et al. Olfactory and gustatory dysfunctions as a clinical presentation of mild-to-moderate forms of the coronavirus disease (COVID-19): A multicenter European study. Eur Arch Otorhinolaryngol 2020;277(8):2251-61. doi: 10.1007/s00405-02005965-1.

19. Speth MM, Singer-Cornelius T, Oberle M, Gengler I, Brockmeier SJ, Sedaghat AR. Olfactory dysfunction and sinonasal symptomatology in COVID-19: Prevalence, severity, timing and associated characteristics. Otolaryngol Head Neck Surg 2020;163(1):114-20. doi: 10.1177/0194599820929185.

20. Hopkins C, Surda P, Whitehead E, Kumar BN Early recovery following new onset anosmia during the COVID-19 pandemic - An observational cohort study. J Otolaryngol Head Neck Surg 2020;49(1):26. doi: 10.1186/s40463-020-00423-8.

21. Moein ST, Hashemian SM, Mansourafshar B, Khorram-Tousi A, Tabarsi P, Doty RL. Smell dysfunction: A biomarker for COVID-19. Int Forum Allergy Rhinol 2020;10(8):944-50. doi: 10.1002/ alr.22587.

22. Hopkins C, Kumar N. Loss of sense of smell as a marker of COVID-19 infection. London, UK: ENTUK, 2020.

23. Kaye R, Chang CWD, Kazahaya K, Brereton J, Denneny JC 3rd. COVID-19 anosmia reporting tool: Initial findings. Otolaryngol Head Neck Surg 2020;163(1):132-34. doi: 10.1177/0194599820922992.

24. Gengler I, Wang JC, Speth MM, Sedaghat AR. Sinonasal pathophysiology of SARS-CoV-2 and COVID-19: A systematic review of the current evidence. Laryngoscope Investig Otolaryngol 2020;5(3):354-59. doi: 10.1002/lio2.384.

25. Giacomelli A, Pezzati L, Conti F, et al. Selfreported olfactory and taste disorders in patients with severe acute respiratory coronavirus 2 infection: A cross-sectional study. Clin Infect Dis 2020;71(15):889-90. doi: 10.1093/cid/ciaa330.

26. Yan $\mathrm{CH}$, Faraji F, Prajapati DP, Ostrander BT, DeConde AS. Self-reported olfactory loss associates with outpatient clinical course in COVID-19. Int Forum Allergy Rhinol 2020;10(7):821-31. doi: 10.1002/alr.22592.

27. Dubé M, Le Coupanec A, Wong AHM, Rini JM, Desforges M, Talbot PJ. Axonal transport enables neuron-to-neuron propagation of human coronavirus OC43. J Virol 2018;92(17):e00404-18. doi: 10.1128/JVI.00404-18.

28. Baig AM, Khaleeq A, Ali U, Syeda H. Evidence of the COVID-19 virus targeting the CNS: Tissue distribution, host-virus interaction, and proposed neurotropic mechanisms. ACS Chem Nerosci 2020;11(7):995-98. doi: 10.1021/ acschemneuro.0c00122.

29. Li YC, Bai WZ, Hashikawa T. The neuroinvasive potential of SARS-CoV2 may play a role in the respiratory failure of COVID-19 patients. J Med Virol 2020;92(6):552-55. doi: 10.1002/jmv.25728.

30. Mao L, Wang M, Chen S, et al. Neurological manifestations of hospitalized patients with COVID-19 in Wuhan, China: A retrospective case series study. medRxi 2020. doi: 10.1101/2020.02.22.20026500. [ePub ahead of print]

31. Brann DH, Tsukahara T, Weinreb $C$, et al. Nonneuronal expression of SARS-CoV-2 entry genes in the olfactory system suggests mechanisms underlying COVID-19-associated anosmia.
Science Advances 2020;6(31):eabc5801. doi: 10.1126/sciadv.abc5801.

32. Tellier R. Aerosol transmission of influenza A virus: A review of new studies. J $\mathrm{R}$ Soc Interface 2009;6 Suppl 6(Suppl 6):S783-90. doi: 10.1098/ rsif.2009.0302.focus.

33. Fiegel J, Clarke R, Edwards DA. Airborne infectious disease and the suppression of pulmonary bioaerosols. Drug Discov Today 2006;11(1-2):51-57. doi: 10.1016/S1359-6446(05)03687-1.

34. Morgenstern J. Aerosols, droplets, and airborne spread: Everything you could possibly want to know. First10EM blog. 6 April 2020. Available at https://first10em.com/aerosols-droplets-andairborne-spread [Accessed 22 August 2020].

35. Judson SD, Munster VJ. Nosocomial transmission of emerging viruses via aerosol-generating medical procedures. Viruses 2019;11(10):940 doi: 10.3390/v11100940

36. Nicas M, Nazaroff WW, Hubbard A. Toward understanding the risk of secondary airborne infection: Emission of respirable pathogens. J Occup Environ Hyg 2005;2(3):143-54.

37. Keene $\mathrm{CH}$. Airborne contagion and air hygiene. William Firth Wells. J School Health 1955;25(9):249. doi: 10.1111/j.1746-1561.1955. tb08015.x.

38. Zhao B, Zhang Z, Li XT. Numerical study of the transport of droplets or particles generated by respiratory system indoors. Build Environ 2005;40(8):1032-39. doi: 10.1016/j. buildenv.2004.09.018.

39. Duguid JP. The numbers and the sites of origin of the droplets expelled during expiratory activities. Edinb Med J 1945;52(11):385-401.

40. Atkinson J, Chartier $Y$, Pessoa-Silva $C L$, Jensen $P$ Li Y, Seto WH. Natural ventilation for infection control in health-care settings. Geneva, $\mathrm{CH}$ : WHO, 2009.

41. Bromage ES. The risks - Know them - Avoid them. Erin Bromage PhD: Disease musings. 7 May 2020. Available at www.erinbromage.com/post/ the-risks-know-them-avoid-them [Accessed 22 August 2020].

42. Institute of Medicine (IOM). Understanding the risk to healthcare personnel. In: Preventing transmission of pandemic influenza and other viral respiratory diseases: Personal protective equipment for healthcare personnel: Update 2010. Washington, DC: National Academies Press (US), 2011;29-70

43. van Doremalen N, Bushmaker T, Morris DH, et al. Aerosol and surface stability of SARSCoV-2 as compared with SARS-CoV-1. N Eng Med 2020;382(16):1564-67. doi: 10.1056/ NEJMc2004973.

44. Guo ZD, Wang ZY, Zhang SF. Aerosol and surface distribution of severe acute respiratory syndrome coronavirus 2 in hospital wards, Wuhan, China 2020. Emerg Infect Dis 2020;26(7):1583-91. doi: 10.3201/eid2607.200885.

45. Fears AC, Klimstra WB, Duprex P, et al. Persistence of severe acute respiratory syndrome coronavirus 2 in aerosol suspensions. Emerg Infect Dis 2020;26(9). doi: 10.3201/eid2609.201806.

46. Workman AD, Jafari A, Welling DB, et al. Airborne aerosol generation during endonasal procedures in the era of COVID-19: Risks and recommendations. Otolaryngol Head Neck Surg 2020:0194599820931805. doi: 10.1177/0194599820931805.

47. Lu D, Wang $H$, Yu R, Yang $H$, Zhao Y. Integrated infection control strategy to minimize nosocomial infection of coronavirus disease 2019 among ENT healthcare workers. J Hosp Infect 2020;104(4):454-55. doi: 10.1016/j. jhin.2020.02.018
48. Patel ZM, Fernandez-Miranda J, Hwang PH, et al. Letter: Precautions for endoscopic transnasal skull base surgery during the COVID-19 pandemic. Neurosurgery 2020;87(1):E66-E7. doi: 10.1093/ neuros/nyaa125

49. Vukkadala N, Qian ZJ, Holsinger FC, Patel ZM, Rosenthal E. COVID-19 and the otolaryngologist: Preliminary evidence-based review. Laryngoscope 2020. doi: 10.1002/lary.28672. [ePub ahead of print]

50. Durante-Mangoni E, Andini R, Bertolino L, et al. Low rate of severe acute respiratory syndrome coronavirus 2 spread among health-care personnel using ordinary personal protection equipment in a medium-incidence setting. Clin Microbiol Infect 2020;26(9):1269-70. doi: 10.1016/j. cmi.2020.04.042.

51. Wong SCY, Kwong RT, Wu TC, et al. Risk of nosocomial transmission of coronavirus disease 2019: An experience in a general ward setting in Hong Kong. J Hosp Infect 2020;105(2):119-27. doi: 10.1016/j.jhin.2020.03.036.

52. Zhang R, Li Y, Zhang AL, Wang Y, Molina MJ. Identifying airborne transmission as the dominant route for the spread of COVID-19. Proc Natl Acad Sci U S A 2020;117(26):14857-63. doi: 10.1073/ pnas.2009637117.

53. Chu DK, Akl EA, Duda S, et al. Physical distancing face masks, and eye protection to prevent personto-person transmission of SARS-CoV-2 and COVID-19: A systematic review and meta-analysis. Lancet 2020;395(10242):1973-87. doi: 10.1016/ S0140-6736(20)31142-9.

54. Cho GS, Moon BJ, Lee BJ, et al. High rates of detection of respiratory viruses in the nasal washes and mucosae of patients with chronic rhinosinusitis. J Clin Microbiol 2013;51(3):979-84. doi: 10.1128/JCM.02806-12.

55. Dong $Y, \mathrm{Mo} X, \mathrm{Hu} Y$, et al. Epidemiological characteristics of 2143 pediatric patients with 2019 coronavirus disease in China. Pediatrics 2020;145(6):e20200702. doi: 10.1542/peds.20200702.

56. Meissner HC. Ask the expert: What are the presenting signs and symptoms in children with confirmed COVID-19 disease? AAP News. 11 May 2020. Available at www.aappublications. org/news/2020/05/11/covid19askexpert051120 [Accessed 22 August 2020].

57. Department of Health. Personal protective equipment (PPE) for the health workforce during COVID-19. Canberra, ACT: DoH, 2020. Available at www.health.gov.au/news/health-alerts/ novel-coronavirus-2019-ncov-health-alert/coronaviruscovid-19-advice-for-the-health-and-aged-care-sector/ personal-protective-equipment-ppe-for-thehealth-workforce-during-covid-19 [Accessed 22 August 2020].

58. Chen X, Liu Y, Gong Y, et al. Perioperative management of patients infected with the novel coronavirus: Recommendation from the joint task force of the Chinese society of anesthesiology and the Chinese association of anesthesiologists. Anesthesiology 2020;132(6):1307-16. doi: 10.1097/ ALN.0000000000003301.

59. Department of Health. Coronavirus disease (COVID-19): Environmental cleaning and disinfection principles for health and residential care facilities. Canberra: $\mathrm{DoH}, 2020$.

60. Therapeutic Goods Administration. Hand sanitisers: Information for consumers. Canberra ACT: DoH, 2020. Available at www.tga.gov. $\mathrm{au} /$ hand-sanitisers-information-consumers [Accessed 22 August 2020].

correspondence ajgp@racgp.org.au 